\title{
Assimilation of porosity in modern bricks by computational means
}

\author{
M. A. Stefanidou \\ Department of Civil Engineering, Aristotle University, Thessaloniki, \\ Greece
}

\begin{abstract}
The study of porosity in building materials is important as porosity is connected to macroscopic mechanical and physical properties which influence the structure behaviour.

A world-wide, simple, quick and low-cost method of recording porosity is through water absorption (RILEM CPC11.3). However, in the case of bricks there is a main disadvantage to using the above mentioned method. The clay material absorbs water and the results are altered. In that case another liquid (maybe an organic solvent) is usually used. This method though, is loosing its creditability and no comparisons can be made with other building materials which are in co-operation with bricks.

Alternatively, in the present work, microscopic analysis through computational means using image analysis is used in order to record porosity in bricks of modern technology. These porosity values are statistically elaborated in order to estimate open porosity which is usually measured using a liquid adsorption. At the same time the geometry of pores and the pore size distribution are recorded.
\end{abstract}

Keywords: bricks, porosity, water absorption, microscopy, image analysis.

\section{Introduction}

Bricks are one of the most ancient construction materials as they were used in the Mediterranean countries for 5 thousand years (Papayianni, Stefanidou [1]). They were used in combination with stone and mortar in the construction of masterpieces such as churches (for example Hagia Sophia 4- $6^{\text {th }}$ century A.D.), protective city walls and also in humble constructions as houses. 
The technology of brick production totally changed after the $19^{\text {th }}$ century when industrial methods were introduced (Gerogiannis [2]). From that point, the brick properties have changed as strength has been increased and consequently the porosity has been decreased (Papayianni and Stefanidou [3]).

In order to record the porosity of bricks different indirect methods are used such as water absorption, mercury porosimeter and nitrogen absorption [4]. All those methods are recording the open porosity that is interconnecting pores which arrive to the surface of the material (Meng [5]).

Porosity has different forms according to the technology used for the bricks construction as is seen in figure 1 .
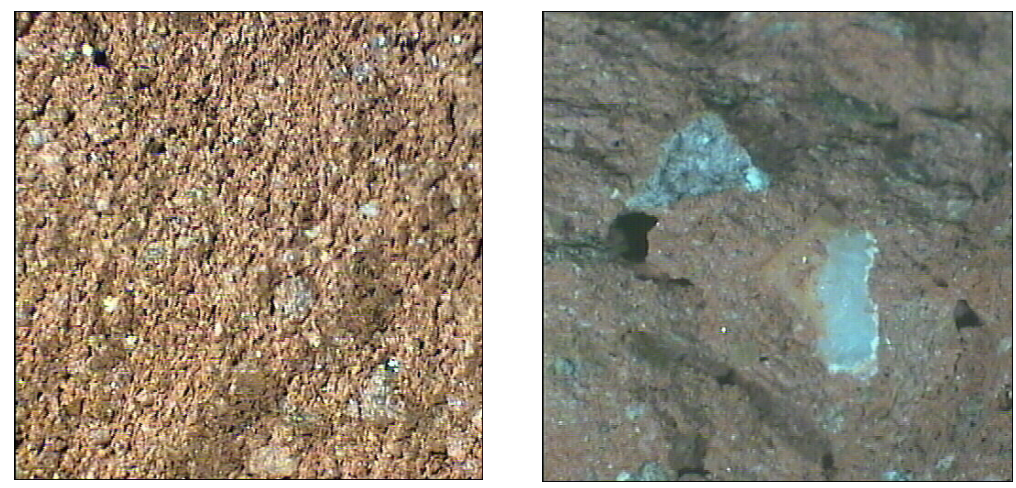

Figure 1: $\quad$ Pores of different size and proportion in the brick structure.

The present paper is a pilot effort to connect the porosity measured by direct ways (through microscopy and image analysis) with the porosity measured by indirect ways such as those mentioned above in modern technology bricks. It is an attempt to correlate total porosity measured microscopically with the open porosity which is recorded through liquid absorption.

\section{Experimental methods}

Thirty brick samples of ten different brick qualities were tested in order to record their mean porosity both by direct and indirect ways. A modified method of the RILEM CPC11.3 was followed in order to estimate open porosity. The original method suggests water as the solvent. In the case of bricks though, water introduces significant error (table 1) as the clay absorbs an adequate quantity of water. Water is substituted by an organic solvent such as heptane. Heptane has a specific gravity 0.68 at the temperature of $20^{\circ} \mathrm{C}$ at which all the experiments were performed.

At the same time, the samples were tested microscopically using a Leica M10 stereoscope at $\mathrm{x} 8$ magnification and a LIDA image analysis system. From each sample 6 measurements were performed and the mean total porosity was measured as recorded in table 1 . 
Table 1: $\quad$ Porosity measurements using different methods.

\begin{tabular}{|r|r|r|r|r|}
\hline & $\begin{array}{l}\text { \% porosity } \\
\text { (water } \\
\text { absorption) }\end{array}$ & $\begin{array}{l}\text { \% porosity } \\
\text { (heptane) }\end{array}$ & $\begin{array}{l}\text { Difference } \\
\text { (water- } \\
\text { heptane) \% }\end{array}$ & $\begin{array}{l}\text { \% porosity } \\
\text { (microscopy) }\end{array}$ \\
\hline 1 & 11.59 & 5.86 & 49.45 & 4.53 \\
\hline 2 & 7.1 & 3.97 & 44.13 & 1.74 \\
\hline 3 & 12.19 & 6.21 & 49.03 & 4.10 \\
\hline 4 & 7.09 & 3.34 & 53.01 & 0.56 \\
\hline 5 & 16.13 & 7.84 & 51.39 & 5.80 \\
\hline 6 & 11.82 & 7.76 & 34.33 & 6.65 \\
\hline 7 & 6.95 & 5.44 & 21.77 & 4.66 \\
\hline 8 & 12.84 & 7.61 & 40.77 & 6.85 \\
\hline 9 & 6.57 & 4.64 & 29.50 & 1.93 \\
\hline 10 & 15.68 & 10.04 & 36.01 & 8.90 \\
\hline
\end{tabular}

An attempt to elaborate statistically the results of the two methods (we consider as $\mathrm{Y}$ the open porosity recorded by liquid absorption and $\mathrm{X}$ the porosity measured by the microscopic method) shows that there is a linear relationship expressed as shown in Figure 2.

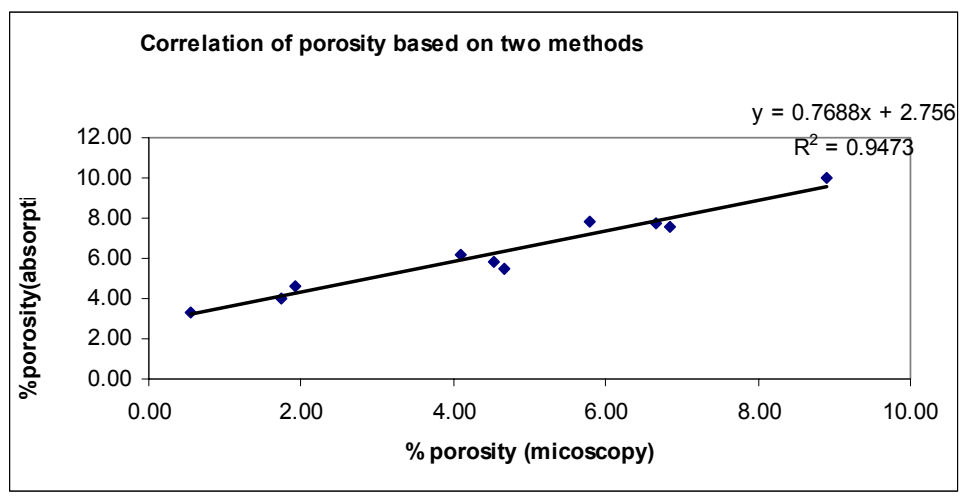

Figure 2: Linear relationship between porosity values of two different methods.

In that case the equation (1) is suggested:

$$
\mathrm{Y}=0.7688 \mathrm{X}+2.756 \quad \mathrm{R}^{2}=0.947
$$

In order to test the creditability of equation (1), a theoretical porosity was estimated using as $\mathrm{X}$ the microscopic values. Comparison between the theoretically estimated porosity and the open porosity measured experimentally shows good relationship (table 2). 
Table 2: $\quad$ Theoretical calculation of porosity using the equation 1 .

\begin{tabular}{|r|r|r|r|r|}
\hline & $\begin{array}{l}\text { Theoretical } \\
\text { (heptane) }\end{array}$ & $\begin{array}{l}\text { Porosity } \\
\text { Porosity } \\
\text { (eqn (1)) }\end{array}$ & $\begin{array}{l}\text { (Heptanio- } \\
\text { theoretical) }\end{array}$ & $\begin{array}{l}\lambda \\
\text { (Hept./theoret) }\end{array}$ \\
\hline 1 & 5.86 & 6.24 & -0.38 & 0.94 \\
\hline 2 & 3.97 & 4.09 & -0.12 & 0.97 \\
\hline 3 & 6.21 & 5.91 & 0.31 & 1.05 \\
\hline 4 & 3.34 & 3.19 & 0.15 & 1.05 \\
\hline 5 & 7.84 & 7.22 & 0.63 & 1.09 \\
\hline 6 & 7.76 & 7.87 & -0.11 & 0.99 \\
\hline 7 & 5.44 & 6.34 & -0.90 & 0.86 \\
\hline 8 & 7.61 & 8.02 & -0.41 & 0.95 \\
\hline 9 & 4.64 & 4.24 & 0.40 & 1.09 \\
\hline 10 & 10.04 & 9.60 & 0.44 & 1.05 \\
\hline average & 6.27 & 6.27 & 0.00 & 1.00 \\
\hline
\end{tabular}

$* a=0.7688$

$\mathrm{b}=2.756$

Table 3: $\quad$ Geometrical characteristics of pores of modern bricks.

\begin{tabular}{|c|c|c|c|}
\hline & $\begin{array}{c}\mathrm{L} \\
(\text { length, } \mu \mathrm{m})\end{array}$ & $\begin{array}{c}\mathrm{B} \\
(\text { breadth }, \mu \mathrm{m})\end{array}$ & $\mathrm{L} / \mathrm{B}$ \\
\hline 1.00 & 58.13 & 29.57 & 1.97 \\
\hline 2.00 & 30.18 & 18.23 & 1.66 \\
\hline 3.00 & 39.63 & 20.16 & 1.97 \\
\hline 4.00 & 37.65 & 18.58 & 2.03 \\
\hline 5.00 & 61.54 & 29.31 & 2.10 \\
\hline 6.00 & 35.42 & 18.60 & 1.90 \\
\hline 7.00 & 41.98 & 21.50 & 1.95 \\
\hline 8.00 & 39.81 & 19.30 & 2.06 \\
\hline 9.00 & 44.80 & 23.60 & 1.90 \\
\hline 10.00 & 36.00 & 19.00 & 1.89 \\
\hline average & 42.51 & 21.79 & 1.94 \\
\hline
\end{tabular}

During microscopic observation additional information concerning the length and the width of the pores are recorded in table 3 . The information is important considering that pore sizes are related to the materials properties and the behaviour under deterioration (Larbi [6], Fitzner [7]).

Measuring the distribution of pores shows that the maximum volume of pores is gathered to the area of $0-55 \mu \mathrm{m}$ (figure 3 ). 


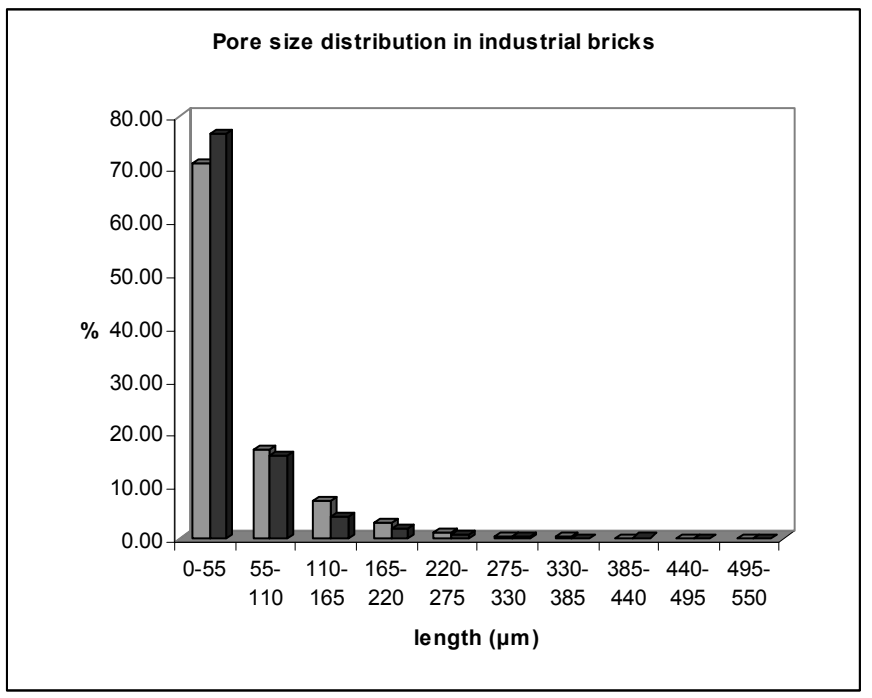

Figure 3: $\quad$ Pore size distribution by image analysis in modern bricks.

\section{Conclusions}

The simple and easy to understand method of liquid absorption in order to measure the open porosity very often introduces errors especially when water is used as solvent. Other organic solvents are costly especially when there are a large number of samples to be tested.

An alternative way to measure porosity microscopically seems that it can give satisfactory results concerning the correlation of the values of porosity measured microscopically, which may be characterized "not practical", to an understandable and easy to use porosity values. Equation (1) is suggested in order to substitute liquid absorption methods.

Taking into account that the size of the samples tested microscopically is small and the time needed to execute the experiments is short, microscopy can be proved to be a quick, easy and affective method for porosity measurements.

\section{Acknowledgements}

The author would like to express her thanks to Vassilis Papanikolaou, civil engineer and Panos Fikos, mathematician for their assistance during the elaboration of the results.

\section{References}

[1] Papayianni I., M. Stefanidou, 1995, "Characteristics of bricks of old masonries" Workshop on Materials for Consolidation and Restoration of 
Monuments and Historical Buildings: Reading, Interpreting and Recovering the Knowledge of Traditional Materials September, Thessaloniki, pp.35-48

[2] Gerogiannis G. "Record and study of bricks of the $19^{\text {th }}-20^{\text {th }}$ century from the area of Thessaloniki" Post-graduates study on Protection, Conservation and Restoration of Cultural Monuments Theesaloniki, November 2006

[3] Papayianni I, Stefanidou M. "Technology and characteristics of fired bricks of $18^{\text {th }}-19^{\text {th }}$ century" 1 st National Congress on Appropriate interventions for the safeguarding of monuments and historical buildings. Hellenic Ministry of Culture/ $4^{\text {th }}$ Ephorate for Modern Monuments, Technical Chamber of Greece 23-25 Nov. 2000 Thessaloniki, pp. 281-292

[4] ISO 15901:2002 Pore size distribution and porosity of solid materials by mercury porosimetry and gas adsorption

[5] Meng B. "Resolution -dependent characterization of interconnected pore systems: development and suitability of a new method" Materials and Structures Vol.27 1994 p.p.63-70

[6] Larbi J.A "Microscopy applied to the diagnosis of the deterioration of brick masonry: Construction and Building Materials, 18, 2004. pp. 299307

[7] Fitzner B. "Porosity analysis -A method for characterization of building stones in different weathering stages" The Engineering Geology of Ancient Works, Monuments and Historical Sites Proceedings of an international symposium organized by the Greek national group of IAEG/ Athens/ 19-23 September 1988 editors P.G. Marinos, G.C. Koukis 